\title{
From Indoctrinating to Counterpoising Carbon Footprint: Role of Communication
}

\author{
Suman Kumar Kasturi ${ }^{1}$ \\ ${ }^{1}$ News Editor (Web), the Hans India (Formerly Senior Non Commissioned Officer at IAF), India \\ Correspondence: Suman Kumar Kasturi, News Editor (Web), the Hans India (Formerly Senior Non Commissioned \\ Officer at IAF), India
}

Received: October 27, 2014

Accepted: November 17, $2014 \quad$ Available online: November 25, 2014

doi:10.11114/ijsss.v3i1.594

URL: http://dx.doi.org/10.11114/ijsss.v3i1.594

\begin{abstract}
As long as humans have interacted with each other and with nature, there has been environmental communication. Worldwide environmental issues ranging from ozone depletion to increased carbon footprint have been threatening our planet and compromising the quality of the lives of humans. In this milieu, environmental education and communication have a remarkable opportunity to accelerate understanding and to mobilize community participation to achieve a change - the reduction of carbon footprint. In a Socio Economic Study (SES), Miller found that media exposure does not occur equally across all social groups and communication through different forms of mass media has different levels of impact on different social groups (Maria A Koelen \& Anne W. Van den Ban 2004, 115). The aim of this paper is to emphasize the role of communication to sensitize the people across the organizations in general, and in India as a whole to reduce the office carbon footprint, while discussing the role of communication in this milieu.
\end{abstract}

Keywords: Carbon Footprint, Satmass Media, Environment, Degradation, Environmental Problems, Green Lifestyles, India, Communication, Mass Media

\section{Introduction}

It is an anthropic principle that the role of environmental communication is increasingly important to inform, educate, and ultimately influence the behavior of the individuals in reducing the carbon footprint. The evolution of the mass communication way backs to many centuries. After Ts'ai Lun invented the paper in 105 AD during theHan Dynasty in China (Kendall Haven 2006, 21), and now with the influence of electronic media, modern gadgets and Information \& Communication Technology (ICT) revolution - there has been an unparalleled impact on the capacity and speed of data/voice/video communication around the world. It has completely transformed the way people and organizations communicate across the world. Since last couple of decades every sector irrespective of whether it is a corporate, government, military or media organization, every organization has extremely come under the influence of the ICT revolution.

This technological transformation has permeated through almost all the organizations - and as a result - the standard of the organizations rose abundantly. Despite the fact that the increased use of computers with intranet and the Internet across the organizations has increased manifold, there is still some orthodox/conventional mindset and hesitation to adopt paperless staff work, e-forms, e-governance and e-administration. To a certain extent, the corporate world has realized the importance of paperless staff work long ago. Many leading global companies have successfully implemented to reap the benefits of the paperless staff work. Nevertheless, the government and other establishments in India even now have not taken up this fact to institutionalize on the same lines by issuing well directed policies and simultaneously launching a strong wave of awareness campaign amongst the staff. The office staff across organizations in India should be motivated towards the larger perspective of environmental sensitive work procedures and practices by embracing technology and thereby prevent the delays involved and drastically cut down on wastages of resources.

In every corner of earth, more and more irregular environmental disasters have been occurring recurrently than ever and most of the disasters can be accounted to carbon footprint (Christine Wamsler 2014, 111). Shafik and Bandyopadhyay estimated Environmental Kuznets Curves (EKCs) for ten different indicators of environmental degradation, including lack of clean water and sanitation, deforestation, municipal waste, and Sulfur Oxides and Carbon 
emissions - and has also come out with the conclusion that carbon emissions account for the greatest proportion of the environmental degradation (Manasranjan Dashmishra 2011, 53).

Environmental communication and the carbon footprint are closely associated with each other. Studies have proven that mass media messages concerning environmental issues have a great impact in changing attitudes of the masses (Susan D. Clayton 2012, 71). So, beginning with a discussion on the significance of the environmental communication, this paper will discuss the role of communication to educate the masses about the importance of reduction in carbon footprint in India.

\section{Working Definition of Carbon Footprint}

The working definition of the carbon footprint considered for this study is the definition given by Championne. The definition is:

"The total sets of greenhouse gas (GHG) emissions caused by an organization, event, product or person" through gradual reduction in usage of paper and other print resources by espousal of technology and electronic alternatives mainly towards the environmental perpetuation while enabling faster action and decision making". (http://thebusinessofsustainability.com.au/glossary-page)

\section{Discussion}

\subsection{Significance of Environmental Communication}

As long as human beings have interacted with each other and with nature, there has been environmental communication. But, practitioners and academicians started using 'Environmental Communication' as a label only since 1969 (Richard et al 2010, 5). Environmental Communication can be defined as:

"The study and practice of how individuals, institutions, societies, and cultures craft, distribute, receive, understand and use messages about the environment and human interactions with the environment" (Richard et al 2010, 13).

This includes a wide range of possible interactions, varying from interpersonal communication to coverage of environmental issues by mass media. Environmental communication is an academic discipline emerged from multidisciplinary fields involving communication, environmental science, risk analysis and management, sociology, political economy, and various allied subjects.

Environmental scholar Cox in the year 2006 in his comprehensive and scholarly "Environmental Communication and the Public Sphere" offered both definitions of informal and formal forms of Environmental Communication as follows:

Informal: A study of the ways in which we communicate about the environment, the effects of this communication our perceptions of both the environment and ourselves, and therefore on our relationship with the natural world'.

Formal: The pragmatic and constitutive vehicle for our understanding of the environment as well as our relationships to the natural world; it is the symbolic medium that we use in constructing environmental problems and negotiating society's different responses to them. (Richard et al 2010,14)

According to Cox, education, attention, persuasion, mobilization, and assistance is the practical outcomes of environmental communication. He argues that environmental communication shapes our perceptions of the natural world as well as our interactions with and impacts on it. In the same context, Corbett in the year 2006 thrusts for a widened idea of environmental communication in her work "Communicating Nature: How we create and Understand Environmental Messages". She hypothesizes environmental communication is:

- Expressed in values, words, actions, and every day practices.

- Individually interpreted and negotiated.

- Historically and culturally rooted.

- Ideologically devised and driven

- Embedded in a dominant societal paradigm that assigns instrumental value to the environment and believes it exists to serve humans.

- Intricately lied to pop culture, particularly advertising and entertainment.

- Framed and reported by the media in a way that generally supports the status quo.

- Mediated and influenced by social institutions little government and business (Richard et al 2010,14) 


\subsection{Office Resource Wastages and Environmental Concerns}

In India, office paper consumption is the one of the most direct and visible hazard to the safety of the environment that ultimately leading to increased carbon footprint. Also, various other office resources like print cartridges and photocopier toners etc. are the major reasons for the increased carbon footprint. Many connected factors like inappropriate cooling/heating systems in the offices, the personal conveyance by which the employees reach their work stations in spite of having the public transportation etc. are the other significant contributors to the increased carbon footprint.

Due to rapid technological advances, many electronic alternatives that can be very cost effective to paper based output have been created. While, in India, from one side the technology is paving a way to reduce consumption of paper, from the other side the consumption of paper is increasing for wasteful print practices and behavior within an organization. Paper consumption is also associated with the consumption of various other resources like printer cartridge. Thus, it makes the environmental impact of paper consumption remarkable.

There is a close connection with the consumption of the paper and carbon footprint. Assuming one ton paper is equal to 400 reams of A4 size paper, manufacturing the same costs us and the environment approximately -1 ton of wood $=8$ trees $=4 \frac{1}{2}$ months energy requirements of a household $=1 / 4$ ton solid garbage waste $=4 \frac{1}{1} 2$ months of a car fuel $=71 / 2 \mathrm{k}$ gallons of water wasted. (https://secure.actewagl.com.au/epayplus/learnaboutpaper.aspx)

Considering this fact and convert the same to know what it means for organizations, we can make out that reducing office paper consumption can have a major positive impact on the environment. It is one of the greatest direct contributions we can make to protect the environment. Towards this, every individual has to set ambitious targets to minimize office carbon footprint. In addition to the protection of environment, to a great extent the cost savings are also can be achieved with a paper reduction campaign, as these costs consist of paper, ink \& toner, maintenance, energy consumption, capital cost and depreciation etc.

The values and culture of the organization is one of the most critical components that will ultimately impact the success of a campaign for reducing the carbon footprint in an office environment. Making a contribution to the environment and indirectly to the society through a committed campaign should be practiced in all organizations as it is happening through Corporate Social Responsibility (CSR) in the corporate world. The organization's receptiveness to change has a direct impact on the success of this concept.

\subsection{Paradoxes to Deal With}

Environmental degradation is a result of the dynamic interplay of socioeconomic, institutional and technological activities. Environmental changes may be driven by many factors varying from social factors, economic factors to institutional factors. As far as India is concerned, high quantity of exhaust gases, deforestation, large number of industries such as mining, chemical effluents, transports, unprecedented construction, secondary pollutants, ruinous agricultural policies, the population explosion and unplanned land-use policies are the underlying causes of environmental degradation (Rishin Mukherjee 2012). Of these mentioned factors that cause environmental degradation, emission of high quantity of exhaust gases and deforestation are closely associated with the paper consumption and carbon footprint.

Carbon dioxide from fossil fuel combustion used in the production of the pulp and paper proves to be the greatest source of greenhouse gas emissions in the paper cycle. Energy is consumed in many stages of the paper production cycle, but greenhouse gas emissions can be readily assessed given that fuel consumption for the pulp and paper industry is already published for most countries in the OECD/IEA (1993) international energy compendia. Carbon dioxide emissions from energy use in the paper industry in 1991 were estimated to be about 316 million tones. (Susan Subak et al 2012, 4)

The carbon dioxide emissions from the pulp and paper industry accounted for a share of $1.2 \%$ of global carbon dioxide from all sources. Pulp and paper industries account for over $4 \%$ of estimated global energy consumption (Ibid).

The above facts give us the evidence to the relationship between paper consumption and carbon footprint. Storing the content in hard copies, apart from backing up the data in a hardcopy format, is the main reason why organizations consume huge quantities of paper in India. This happens mainly because most of the conventional organizations across India still maintain hard copies in files and preserve them for a stipulated period, before which they are destroyed by either burning or shredding. There is a requirement to review these policies and associated practices in order to validate the need to print and survey the acceptability of electronic alternatives. Nowadays, technology has advanced so much that printed reports are seldom necessary. Without a proper review of existing guidelines of an organization, we often land up in the duplicating of the work without any specific purpose assigned to such an act. 
The technological advancement is not so pleasant and has its own hitches and ill effects on the environment as brought out in a recent study carried out by the Centre for Energy-Efficient Telecommunications and Bell Labs. As reported, the Internet and other hardware elements of ICT industry annually produces over 830 million tons of carbon dioxide $\left(\mathrm{CO}_{2}\right)$, the main greenhouse gas, and is expected to double by 2020 (http://articles.economictimes.indiatimes.com/2013-01-06/news/36173897_1_ict-tonnes-of-carbon-dioxide-energy-cons umption). They also explained that the ICT industry - which delivers the Internet, video, voice and other cloud services - produces about $2 \%$ of global $\mathrm{CO}_{2}$ emissions, the same as the aviation industry produces. New models of emission control and energy consumption are unfolding that could help reduce their carbon footprint and thereby mitigate the effects on the environment (Ibid).

\subsection{A Point to Ponder...}

In most of the organizations, it has become a common practice that without considering whether a printout is required actually, the employees hit the print button. The main reason to have a printout in hand is to see things on paper, as hoarding information in hands provides the information readily available in hand, but so often this impulsive need to print is pointless. About $50 \%$ or more of pages printed/copied (http://www.makeuseof.com/tag/printing-emails/) are never looked at or used in any organization. For example: consider the number of times an almost completely blank "page 2 of 2" comes out of our printer when printing documents. There is a need to give subtle reminders in the form of messages on formation web pages and as watermarks embedded on document soft copies to discourage needless printing practices. By this, we might start a small but a movement of its stature for a change in organizations across India. For all this to happen, effective communication is a must.

\section{Communication for Reduction of Carbon Footprint}

\subsection{Need for Communicating Reduction in Carbon Footprint}

Having a concern for the carbon footprint reduction and following the same in both in letter and spirit is the ultimate way to protect the environment and retain the sustainable development. The concept of sustainable development ways backs its roots in the fourth century BC. It is evident by Chanakya's opinion - "Stability of an empire depends on the stability of its environment" (VV Raoet al 2004, 82). He has emphasized the concept of sustainable development. Sustainable development is nothing but proper usage of the resources available naturally, for the continuous development to satisfy the human needs. Such an act should ensure damage is not caused to the environment; also the natural resources are not to be misused. Here the term environment does not necessarily imply trees, animals and the ecosystem only. It is literally about all the entities on which the human life subsists. In other words, sustainable development may be defined as the ability of physical development and environmental impacts to sustain long term habitation on the planet earth by human and other indigenous species (Roosa \& Stephen 2008, 44).

In the purview of most of the environmental scientists, the world is a vast system of relationships in which many small changes can accumulate to become significant global changes (Deanna J Richards et al 2001, 191). Any method of information sharing like reduction in carbon footprint succeeded in addressing environmental issues needs to be shared worldwide in part not only because of its global implications, but also because observed environmental changes in one locality can be related to changes in another. If solutions to our growing environmental challenges across the world are to be found, information is to be shared quickly. The many-to-many model of global information sharing can be particularly useful for those seeking information about sustainable and ecologically progressive practices (Ibid).

\subsection{Information Sharing as a Force for Reduction in Carbon Footprint}

The responsibility for climate change due to reduction in carbon footprint does not rest with the government alone, but should involve all people, at all levels. Governments can apply several tools, especially, adapting environmental communication to motivate businesses, communities and individuals adjust their behavior in ways that promote environmental factors - mostly about the reduction in carbon footprint. Effective communication on carbon footprint reduction is therefore necessary in order to gain public support and thus protect the environment. As carbon footprint is a global concern with wide-ranging impacts, it is essential that the relevant messages are communicated successfully with many different groups including residents, partners, opinion leaders, and stakeholders. Mass Media play a vital role in addressing these issues, greatly.

Effectively communicating the aftermath of carbon footprint and issues related to sustainable resources management is not a straight forward process. It can often be a very difficult task to share information among the masses, scattered in a range of groups. This is especially so, when we try to communicate about environmental matters with people consisting of the audience who have no understanding of the relationship between our wellbeing and environmental matters.

As Liverman et al, the eminent geoscientists observed: 
Effective communication may require different approaches depending upon the educational background of the audience being addressed. The audience can be broadly classified as scientists, government administrators and the general public. The communication process is complicated further by the difficulty that geoscientists can have in identifying the appropriate communication pathways to use if their endeavors to be successful. It raises questions of exactly who they should talk with, and whether one organization can open better communication opportunities than other (Liverman et al 2008, 179-184).

Environmental protection is a complicated issue. The complexity of the issue makes it difficult to understand, and causes controversy. It is also difficult to discern environmental changes over a stipulated period. The messages that need to be clearly communicated are:

- That environmental degradation is real and is messing up the planet Earth;

- It is possible to adapt to the preventive measures causing damage to the environment;

- There are risks to the "do-nothing" option in the context of environmental degradation.

It is also important to recognize the potential conflicts that exist between the long-term changes environmental protection will bring and the short-term priorities that individuals and organizations work to. The same can be achieved through:

- Promoting credible sources of information;

- Preparing and utilizing material on environmental protection;

- Integrating the environmental protection issue in related communications;

- Responding to questions and requests for information;

- Proactive outreach to community groups and leaders.

\section{Communicating Environmental Factors Using Mass Media in Indian Setting}

In creating awareness about carbon footprint, environment and conservation of natural resources, mass media can play a crucial role. Various channels of mass communication take on the task - an important factor. The electronic media can identify and bring to a halt forces affecting the natural and even the artifact environment. The need is to mobilize the public mind to protect environment by various means that include a cutback in carbon footprint. Studies have proven that mass media messages concerning environmental issues have a great impact in changing attitudes of the masses (Susan D. Clayton 2012, 71)

The governing bodies in India should undertake media research and media planning in accordance with the attitude of the people of India, apart from considering the influence of various aspects related to different geographic levels urban, semi-urban and rural, on the masses of Indian society. These could steer campaign objectives, measure the effectiveness of mass media programs, provide the information most relevant to the efficient use of mass media, and deliver programs on conservation of resources and maintenance of environmental quality.

Targeting the communication by groups can often be crucial to increasing awareness. Therefore, the most appropriate media need to be selected for each group of audience. There is often little statistical difference of climate change awareness among different communities, so selecting particular groupings can be difficult. However, the fact that there is a general low level of awareness does mean that some approaches may be as useful across the whole population. Environmental protection policies and measures should be integrated with other environmental issues and mainstream policies. The governing bodies in India should maintain innovative flexibility in policy making to deal with uncertainty. The communication strategy concerning environmental factors should include following key messages:

- Everyone has a role to play - a role by enhancing their contribution to environmental protection.

- Environmental protection will impact everyone - everyone needs to adapt.

Important public relations activities such as those appended below are very important while communicating the environmental factors using mass media in Indian setting.

- Engagement of the audience fully in related activities;

- Provide credibility through approval of third parties, by way of diffusing success stories;

- Attract media attention, thereby promoting the project;

- Display obligation to all stakeholders through demonstrations;

- Create and maintain respectability in the eyes of the stakeholders. 
A key part of successful promotion lies in knowing the most effective channels of mass communication to reach the target audience. The pros and cons of the available options have to be considered, well before media planning is done.

Appropriate use of the press, radio, television and the Internet will fetch the desired results. The priority of the communication is to motivate simple changes needed to be done, in order to safeguard the environment. The mixed media of visual press, aural radio, and audio-visual television can be used to convey a variety of messages and stimulate to action in different ways. All media usage needs to be cost effective in their reach of the target audience and the communities as a whole. The target audience for the communicated messages through various mass media is varied and dissimilar. Keeping in view of this fact, the program designing is required to be planned.

Television has in an important role in communicating environmental messages. Especially satellite television has proven its impeccable impact in informing the masses in Indian setting (Suman K Kasturi 2013, 237). Radio broadcasts, especially on local stations are both more affordable and can be used to target more specific audiences like agrarian societies. It is a common practice in India that public like to receive information via leaflets or pamphlets wherein public participation is intended. Also, they are relatively inexpensive to produce and provide. Posters in particular are suitable for placing in public places. There are however, sustainability questions surrounding the publication of leaflets, as publication of leaflets and posters themselves is against the preaching reduction in carbon footprint. Due to the increase in availability of the access to the Internet, the ability to provide up-to-date and creative information has become a reality. A website can have lower cost advantages and can act as a primary focus for campaigns and a source of contact for the target audience (working in ICT environment). The Internet offers the greatest opportunity for the growth of realistic, workable, global information-sharing system. The information thus received through the Internet can be disseminated locally through various other mass media channels, as deems fit.

The target audience for various mass media in the context of diffusing information related to carbon footprint reduction, specifically, and other environmental factors in general is shown in Fig 1.

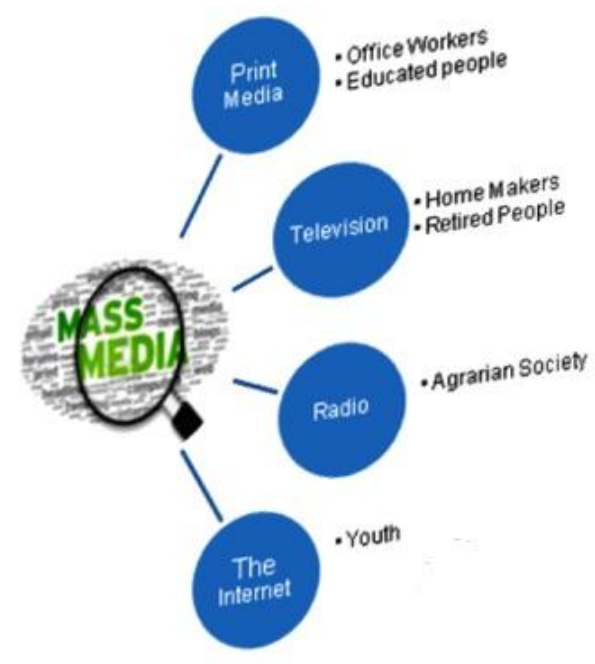

Figure 1. Target Audience of Various Mass Media in Diffusing

Information of Environmental Protection through Reduction in Carbon Footprint

(Source: Personal files of Author)

In addition to the use of mass media, other methods like direct engagement and advertising can also be used to disseminate the environmental factors. Direct engagement is used to communicate campaign messages directly to the target audience (in this case of carbon footprint, it is the employees of all organizations across the country) through a number of channels, the most appropriate of which will be derived by the target audience. The success of this tactic will be resource dependent. Advertising is a non-personal communication tool to foremost aim of creating awareness. Although it doesn't focus on a specific target audience, it can have a powerful impact and a wide reach. Traditional awareness raising campaigns rely extensively on advertising using on any or a combination of radio, TV, newspapers, posters, leaflets and the Internet. 


\section{Action Plan for Communicating Environmental Factors}

The action plan for communicating the environmental factors involving mass media is proposed in the following five stages:

$\begin{array}{lll}\text { Stage 1 } & \rightarrow & \text { Preparation } \\ \text { Stage 2 } & \rightarrow & \text { Evaluation } \\ \text { Stage 3 } & \rightarrow & \text { Understanding \& Action Planning } \\ \text { Stage 4 } & \rightarrow & \text { Implementation } \\ \text { Stage 5 } & \rightarrow & \text { Re-Evaluation }\end{array}$

Stage 1-Preaparation: Depending upon the target audience and the message intended for communicating the environmental protection i.e. reduction of carbon footprint, the media message and media design are to be considered.

Stage 2-Evaluation: Keeping every aspect concerning the issues of communicating the environmental protection, all mass media channels need to be evaluated for their effectiveness.

Stage 3-Planning: A thorough understanding of all intricacies involved in the process of communicating the environmental messages through mass media and other associated areas is required, before an action plan is made ready in this stage.

Stage 4-Implementation: Taking into account of all guidelines, in the fourth stage the plan developed in stage 3 is to be executed.

Stage 5-Re-Evaluation: In this last stage of the action plan, the results need to be re-evaluated. In case of any modifications required, all stages are to be repeated until the desired results are achieved.

Fig. 2 depicts the stages involved in the action plan for communicating environmental factors as a cyclic process.

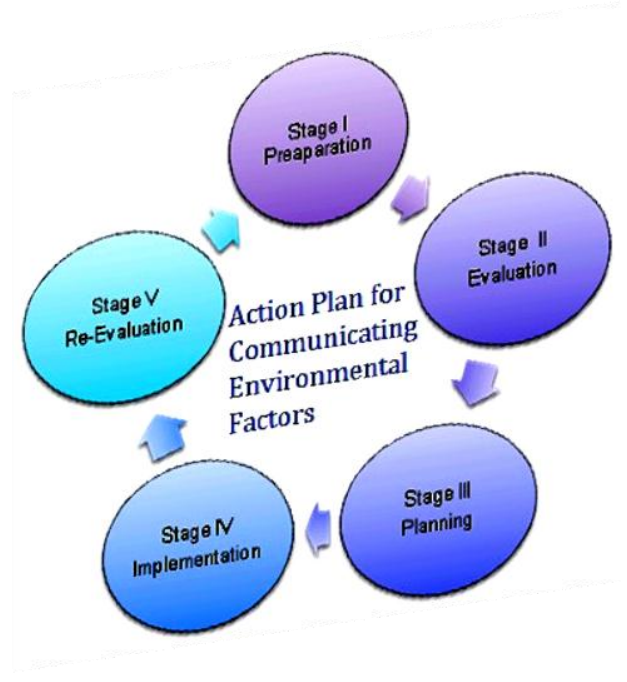

Figure 2. Cyclic Process of Stages of Action Plan for

Communicating Environmental Factors on Reduction in Carbon Footprint

(Source: Personal files of Author)

\section{Conclusion}

As long as humans have interacted with each other and with nature, there has been environmental communication. Although environmental degradation has attracted substantial attention from people, widespread environmental problems still influence the lives of people across the world, every year. As a responsible global citizen, every individual must be aware that the environmental problems cannot be solved by one person but require the unity and cooperation of all people. In order to achieve a greener and cleaner environmental goal, it is time to combat the environmental problems like reduction in carbon footprint and work cooperatively to protect the current ecological environment. The government bodies at various levels need to formulate communication policy to bring awareness 
among the masses. Studies have proven that mass media messages concerning environmental issues have a great impact in changing attitudes of the masses (Susan D. Clayton 2012, 71).

Many studies carried out around the world have tried their best to bring complex but important issues of the environment into limelight. Also, taking the advantage of Satmass Media (Suman K Kasturi 2013, 183) (a word coined by Dr. Suman Kumar Kasturi to indicate the mass media that work in conjunction satellite communications), we can only hope that more and more mass media programs must come forward and spread the awareness regarding environmental issues among a vast array of concerned citizens of India thus paving a way for environmental protection.

\section{References}

Clayton, S. D. (2012). The Oxford Handbook of Environmental and Conservation Psychology. New York: Oxford University Press. http://dx.doi.org/10.1093/oxfordhb/9780199733026.001.0001

Dashmishra, M. (2011). Political Economy of Devlopment\& Environmental Degradation in India. New Delhi: Concept Publishing Company Pvt Ltd.

Glossary: The Business of Sustainability. (2014). Carbon Footprint. Retrieved October 08 2014, from http://thebusinessofsustainability.com.au/glossary-page/

Haven, K. F. (2006). 100 Greatest Science Inventions of All Time. Westport: Libraries Unlimited.

Jurin, R. R., Roush, D., \& Danter, J. (2010). Environmental Communication: Skills and Principles for Natural source Mangers, Scientists, and Engineers. New York: Springer Science Business Media.

Kasturi, S. K. (2013). Satellite Television and the Internet: History, Development and Impact. New Delhi: Kanishka Publishers.

Koelen, M. A., \& Ban, A. W. V. D. (2004). Health Education and Health Promotion. Wageningen: Wageningen Academic Publishers. http://dx.doi.org/10.3920/978-90-8686-665-6

Liverman, D. G. E., Perira, C. P. G., \& Marker, B. (2008). Communicating Environmental Geo Science. London: Spiral Publications.

Makeuseof. (2012). Everything You Need to Know About Printing E-mails. Retrieved November 10, 2014, from http://www.makeuseof.com/tag/printing-emails/

Mukherjee, R. (2013). Top 10 Causes of Environmental. Retrieved October 08, 2014, from http://www.youthkiawaaz.com/2012/01/top-10-causes-of-environmental-damage

PTI Report. (2013). Internet Emits 830 Million Tonnes of Carbon Dioxide. Retrieved October 08 2014, from http://articles.economictimes.indiatimes.com/2013-01-06/news/36173897_1_ict-tonnes-of-carbon-dioxide-en ergy-consumption

Rao, V. V., et al. (2004). Education in India.New Delhi:Discovery Publishing House.

Richards, D. J., Allenby, B. R., \& Compton, W. D. (2001). Natural Academy of Engineering, Information Systems and the Environment. Washington: National Academics.

Roosa., \& Stephen, A. (2008). Sustainable Development: Handbook. Lilburn:The Fairmont Press, Inc.

Saving Paper. (2013). Saving Trees with Epayplus. https://secure.actewagl.com.au/epayplus/learnaboutpaper.aspx

Subak, S., Craighill, A., Guthrie, M., \& Kelly, M. (2012). Towards Sustainable Paper Cycle-the Paper Industry and Global Warming. New York: World Business Council for Sustainable Development.

Wamsler, C. (2014). Cities, Disaster Risk and Adaptation. New York: Routledge.

\section{$(\mathrm{cc}) \mathrm{BY}$}

This work is licensed under a Creative Commons Attribution 3.0 License. 